\title{
Content Validation of the Instrument Nursing Care Technology in the Prevention and Management of Hemorrhage in the Third Stage of Labor
}

\author{
Teixeira Rangel RC1, da Costa Leitão MN2, Godinho Bertoncello KC , \\ Echevarria-Guanilo ME3 ${ }^{3}$, Delziovo $\mathrm{CR}^{5}$, Lynn FA 6 and de Souza ML7* \\ 1Federal University of Santa Catarina, Florianópolis / SC, Brazil. Professor of the \\ Undergraduate Nursing Course at the University of Vale do Itajaí \\ ${ }^{2}$ Portuguese Catholic University, Nursing School of Coimbra, Portugal \\ ${ }^{3}$ Department of Nursing, University Federal de Santa Catarina, Brazil \\ ${ }^{4}$ Federal University of Santa Catarina (UFSC), Brazil \\ ${ }^{5}$ School of Nursing and Midwifery, Queen's University Belfast \\ ${ }^{6}$ Department of Public Health, Professor, University Federal de Santa Catarina, Brazil
}

*Corresponding author: Maria de Lourdes de Souza, President of the Repensul Institute, Health Sciences Center of the Federal University of Santa Catarina, Rua Delfino Conti, s/n-Bairro Trindade, CEP 88040-370, Florianópolis/SC - Brasil, Tel: +55(48)991618333; Email: repensul@uol.com.br

\section{Abstract}

Objective: to have obstetrical nurse experts analyze the composition of the instrument for nursing care technology in the prevention and management of hemorrhage in the third stage of labor and apply assessment criteria to validate it.

Method: Methodological, quantitative, descriptive study. The instrument, based on an integrative and a systematic review, was divided into five axes, 20 domains, and 81 items. The instrument was sent to experts who assessed it using an electronic form (Google forms) with a seven-point Likert scale ranging from 7-totally agree to 1-totally disagree. Analysis included Cronbach's Alpha coefficient index (>0.70) and Content Validity Index (CVI>0.80).

Results: All ten criteria used to assess the instrument, which were analyzed by the 20 experts, presented very high Cronbach's Alphas. The criteria were: clarity; coherence; scientific writing; relevance; sequence; homogeneity and current ness (Alpha 0.96); scope; criticality of items, and objectivity (0.95), that is, the experts considered the items to have very high reliability. The CVIs were also considered to be excellent. The items understanding, consistency, criticality of items, scientific writing, relevance and current ness of content obtained the highest CVIs (0.95); sequence and homogeneity obtained a CVI equal to 0.90; and objectivity and clarity presented the lowest index: 0.85 .

Conclusion: The instrument was validated by obstetrical nurses and considered to be highly reliable (total alpha equal to 0.96 and CVI equal to 0.92).

Keywords: Nursing care; Obstetric Nursing; Technology 


\section{Nursing \& Healthcare International Journal}

\section{Introduction}

Maternal mortality is an indicator of the life conditions and health care provided to a population; almost all such deaths are avoidable and occur in developing countries. Maternal mortality indicates gender inequalities, poor access to education, to proper nutrition and health, and its preventable nature should be taken into account when inter sectoral actions are implemented to ensure access to quality health care for the entire population [1]. The worldwide maternal mortality ratio (MMR) fell approximately $44 \%$ in the past 25 years, from 385 deaths $/ 100,000$ live births in 1990 to 216 deaths/100,000 live births in 2015. The goal for 2015 was not achieved in Brazil; there should have been a decrease to a maximum of 35 maternal deaths/100,000 live births [1].

Postpartum hemorrhage (PPH) is the most common form of obstetrical bleeding and one of the primary causes of maternal morbidity and mortality. Obstetrical hemorrhage is the main cause of maternal deaths worldwide. Its incidence varies among countries but, according to the World Health Organization, it accounts for $27 \%$ of the direct obstetrical maternal deaths, especially in the postpartum stage; in some countries, it accounts for more than 50\%. Even in developed countries, hemorrhaging is among the three primary causes of maternal death [2-7]. Even though $\mathrm{PPH}$ rates vary according to the economic conditions of countries (between high- and low-income countries), PPH is estimated to affect $6 \%$ of births [8].

Even though the use of uterotonics is a preventive measure used to treat postpartum hemorrhage $[9,10]$, there has been an increase in the global PPH rates in the last 25 years in countries such as Australia, Canada, United Kingdom, Ireland and the United States [11-13].

Primary hemorrhage is defined as excessive bleeding in the first 24 hours after birth, blood loss greater than $500 \mathrm{ml}$ after vaginal delivery and blood loss greater than $1,000 \mathrm{ml}$ after a C-section. PPH may be minor (500$1000 \mathrm{ml}$ ) or major (more than $1,000 \mathrm{ml}$ ). Major PPH is classified as moderate $(1000-2000 \mathrm{ml})$ or severe (more than $2000 \mathrm{ml}$ ) bleeding. Secondary PPH is abnormal or excessive bleeding from the birth canal between 24 hours and 12 weeks after birth [5].

Due to its high impact on women's and infants' health, decreasing the rates of PPH is one of the main goals of international health organizations. One of the strategies is to properly identify women who are at greater risk of experiencing excessive blood loss after birth, in an attempt to promote a more rigorous surveillance of this population. Even though obstetrical bleeding may occur unexpectedly, some studies report specific risk factors for PPH [13-19].

All pregnancies, even 20-week pregnancies, may present the risk of PPH. Most cases do not present identifiable risk factors, thus monitoring and early identification of bleeding is necessary. Antepartum risk factors account for $65 \%$ of PPH cases and include being older than 40 years of age; an only child; having a suspicion of or having premature placental abruption; known previous placenta; multiple gestation; preeclampsia/gestational hypertension; prior $\mathrm{PPH}$; obesity; and anemia, while intrapartum risk factors include: retained placenta; operative vaginal birth, mediolateral episiotomy; prolonged labor; large infant (>4kg); and pyrexia during labor $[5,17,20-22]$.

Being aware of antepartum and intrapartum risk factors is essential to preventing and managing potentially massive bleeding. The main cause of early PPH in $70 \%$ of cases is uterine atony, followed by uterine rupture, placenta retention, trauma of the soft birth canal (instrumental delivery, spontaneous trauma, episiotomy), disseminated intravascular coagulation, and uterine inversion, while the causes of late PPH include: endometritis and retention of ovary remains. The mnemonic of 4Ts is useful to remembering the causes: tonus, tissue, trauma, and thrombosis.

PPH is the most significant complication during the puerperal pregnancy cycle, especially in the third stage of labor. It requires recognizing antepartum and intrapartum risk factors, as well as being aware of care actions able to prevent, manage, early diagnose, and treat the condition $[21,23]$. For that, the development and validation of an instrument intended to record timely and appropriate interventions will positively impact morbidity and mortality associated with this obstetrical complication.

Thus, the objectives of this study included: to propose an instrument addressing the actions of nurses to prevent and manage hemorrhaging in the third stage of labor, and validate its content among nurse experts, by analyzing its psychometric properties so that preventive and control measures can be included in the routines of all workers assisting women during labor and deliveries. 


\section{Nursing \& Healthcare International Journal}

\section{Method}

This methodological, descriptive study with a quantitative approach was intended to validate the content of an instrument addressing nursing care technology in the prevention and management of hemorrhage in the third stage of labor.

This type of study is intended to investigate methods to obtain, organize and analyze data, develop, validate and assess instruments and research techniques. Note that the goal of this type of study is to develop a reliable instrument that can be later used by other researchers [24-26].

The instrument's content was validated in two stages: first, during the development of the instrument, while the second stage was the phase when experts quantified and assessed the process. An integrative and systematic review was conducted to identify the instrument's content and establish how many domains and care actions would be necessary to organize such actions ultimately. The second stage consisted of content validation. The experts assessed the instrument and actions proposed according to the importance of the domains and their respective content [27]. In addition to the instrument's content, clarity and objectivity, ten criteria proposed by Pasquali [28] were also assessed.

The judges who validated content were identified from a list of Obstetric Nurses registered in the Brazilian Nursing Council as experts; a total of 195 professionals are listed. Inclusion criteria were: having a curriculum in the Lattes Platform with an email available; working in one of the following: an Obstetrical Unit; a Natural Birth Center; rooming-in; in a Planned delivery team; Undergraduate teaching; or high school teaching.

Those who agreed to participate in the study were asked to confirm their consent through email and sign a free and informed consent form. If no response was obtained, a new invitation was resent every seven days until a sample of 20 participants was obtained. The recommendations provided by Pasquali [29] concerning the number of judges (from six to 20) were adopted.

After agreeing to participate in the study, each expert completed an electronic form, developed via Google forms, divided into three parts:

Part 1: Characterization of the judges.

Part 2: Instrument to assess each item in regard to content. A total of 81 care actions were divided into 20 domains based on the priority of nursing interventions, which were assessed on a seven-point Likert scale. The experts rated how appropriate care actions proposed in each domain were (1=inappropriate and incomplete; $2=$ requires major review to become appropriate and complete; $3=$ requires minor review to be appropriate and complete; 4=neither inappropriate, nor appropriate; $5=$ appropriate and complete; 6=very appropriate and complete; $7=$ totally appropriate and complete). After this, the experts were invited to provide the content they considered necessary to be added to the domains.

The form, developed online, was called: "Tecnologia do cuidado do enfermeiro na prevenção e no controle da hemorragia no terceiro período do parto: validação de conteúdo" [Nursing Care Technology in the prevention and management of hemorrhage in the third stage of labor: content validation]. Different types of answers could be selected, for instance: checkboxes, drop-down lists, multiple choice, plain text, or paragraph text field, which allows respondents to provide their opinion and write longer answers.

Part 3: Assessment of the instrument in terms of its composition. This part of the instrument addressed 10 criteria recommended by Pasquali [28], namely: scope; clarity; coherence; criticality of items; objectivity; scientific redaction; relevance; sequence; homogeneity; and currentness.

A seven-point Likert scale (ranging from 1-totally disagree to 7-totally agree) followed each of the 10 items. The answers provided by the experts were entered into a Microsoft Excel (2010) spreadsheet and the scores obtained by each item were computed. Cronbach's alpha and the Content Validity Index (CVI) were used to validate the instrument in regard to the relevance of its items and the instrument as a whole, obtained by inter-rater agreement. Validation is obtained when a group reaches a consensus in regard to a given phenomenon. Such a group is composed of experts, that is, professionals effectively engaged in the field in which a study is being developed [30].

The Cronbach's alpha index ranges from 0 to 1 and estimates how uniformly items contribute to the unweighted sum of the instrument. This property is known as internal consistency, hence, alpha is interpreted as the mean coefficient of all estimates of internal consistency one would obtain if performing all the scale's possible divisions [31]. According to Freitas, et al. [32] and Freitas, et al. [33], alpha is considered satisfactory when $\alpha \geq 0.70$, which is the cutoff point used in this study. 
Content validation is intended to measure whether the study represents a measure of reality such as it is. The theoretical analysis is performed by the experts and is intended to establish understanding of items and their pertinence to the construct one intends to measure [28].

According to Rubio et al. [34], the CVI assesses agreement among judges in regard to the representativeness of the measure in relation to the content it addresses; which is calculated dividing the number of judges who agreed with the item by the total number of judges (CVI of each item).

Agreement or disagreement was verified; that is, the proportion of judges who rated the item as valid (with a score greater than 5 in the Likert scale) to remain in the protocol was verified in relation to the total number of judges. A CVI greater than 0.80 was necessary for an item to remain in the instrument [35].
Ethical guidelines were taken into account according to what is established in Resolution No. 446/2012, Brazilian Council of Health [36]. This study was submitted to and approved by the Institutional Review Board at UFSC, via Platform Brasil, No. 169.110 from October 10, 2012 - CAAE n. 03586312.0.0000.0121. CONEP was also consulted (No. 120.343, de 08/10/2012).

\section{Results}

The 20 experts scored all the items using a seven-point Likert scale ranging from 1-totally disagree to 7-totally agree Table 1.

Table 1 Judges' assessments of the instrument nursing care technology in the prevention and management of hemorrhage in the third stage of labor in regard to its composition according to 10 criteria proposed by Pasquali [28]. Florianópolis, SC, Brazil 2019.

\begin{tabular}{|c|c|c|c|c|c|c|c|c|c|c|c|c|}
\hline $\begin{array}{l}\text { 蒠 } \\
\text { 全 }\end{array}$ & 帘 & 尝 & 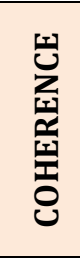 & 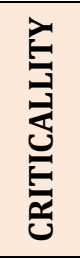 & 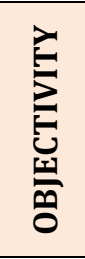 & 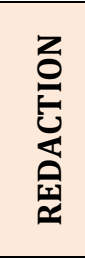 & 预 & 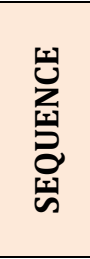 & 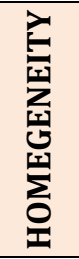 & 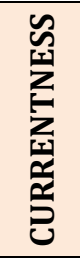 & TOTAL & $\%$ \\
\hline 1 & 6 & 5 & 5 & 5 & 5 & 5 & 7 & 6 & 7 & 7 & 58 & 83 \\
\hline 2 & 7 & 7 & 7 & 7 & 7 & 7 & 7 & 7 & 7 & 7 & 70 & 100 \\
\hline 3 & 7 & 7 & 7 & 7 & 7 & 6 & 7 & 7 & 7 & 7 & 69 & 98.6 \\
\hline 4 & 7 & 7 & 7 & 7 & 7 & 7 & 7 & 7 & 7 & 7 & 70 & 100 \\
\hline 5 & 7 & 6 & 6 & 7 & 6 & 7 & 6 & 7 & 5 & 6 & 63 & 90 \\
\hline 6 & 7 & 7 & 4 & 6 & 7 & 5 & 7 & 7 & 6 & 5 & 61 & 87.1 \\
\hline 7 & 7 & 7 & 7 & 7 & 6 & 7 & 7 & 7 & 7 & 7 & 69 & 98.6 \\
\hline 8 & 5 & 5 & 5 & 6 & 5 & 5 & 7 & 5 & 4 & 6 & 53 & 75.7 \\
\hline 9 & 7 & 7 & 7 & 7 & 7 & 7 & 7 & 7 & 7 & 7 & 70 & 100 \\
\hline 10 & 6 & 5 & 7 & 7 & 7 & 7 & 7 & 6 & 7 & 7 & 66 & 94.3 \\
\hline 11 & 6 & 6 & 7 & 6 & 7 & 6 & 6 & 6 & 6 & 7 & 63 & 90 \\
\hline 12 & 5 & 3 & 5 & 5 & 3 & 5 & 5 & 3 & 3 & 6 & 43 & 61.4 \\
\hline 13 & 7 & 7 & 7 & 6 & 6 & 7 & 7 & 5 & 6 & 7 & 65 & 92.8 \\
\hline 14 & 5 & 4 & 5 & 5 & 4 & 5 & 5 & 5 & 5 & 5 & 48 & 68.6 \\
\hline 15 & 7 & 7 & 7 & 7 & 7 & 7 & 7 & 7 & 7 & 7 & 70 & 100 \\
\hline 16 & 5 & 5 & 5 & 5 & 5 & 5 & 5 & 5 & 5 & 5 & 50 & 71.4 \\
\hline 17 & 7 & 5 & 7 & 7 & 7 & 6 & 7 & 7 & 7 & 7 & 67 & 95.7 \\
\hline 18 & 4 & 4 & 5 & 4 & 4 & 4 & 4 & 4 & 5 & 4 & 42 & 60 \\
\hline 19 & 7 & 6 & 7 & 7 & 7 & 7 & 7 & 7 & 7 & 7 & 69 & 98.6 \\
\hline 20 & 6 & 6 & 6 & 6 & 6 & 6 & 7 & 5 & 6 & 7 & 61 & 87.1 \\
\hline TOTAL & 125 & $\#$ & 123 & 124 & 120 & 121 & 129 & 120 & 121 & 128 & \multirow{2}{*}{1227} & \multirow{2}{*}{87.6} \\
\hline$\%$ & 89 & 83 & 87.9 & 89 & 85.7 & 86.4 & 92.1 & 85.7 & 86 & 91.4 & & \\
\hline
\end{tabular}

Source: Developed by the author (2019).

Table 1: Presents the assessment of the experts in regard to the instrument's composition according the 10 criteria proposed by Pasquali [28]. 
The items relevance and currentness were the ones assessed the highest by the judges, with $92.1 \%$ and $91.4 \%$, respectively; followed by the items scope, criticality and coherence, with approval rates of $89.3 \%, 88.6 \%$ and $87.9 \%$, respectively; while the items concerning scientific redaction and homogeneity obtained $86.4 \%$ approval; objectivity and sequence obtained $85.7 \%$; and clarity was the item with the lowest level of approval, with $82.9 \%$.

Cronbach's alpha and Content Validity Index (CVI) were the reliability measures used to assess the content of the instrument nursing care technology in the prevention and management of hemorrhage in the third stage of labor, conducted by 20 judges (Table 2).

\begin{tabular}{|c|c|c|c|c|c|}
\hline 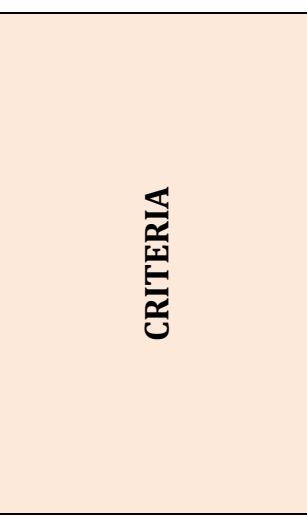 & $\sum_{\sum}^{z}$ & 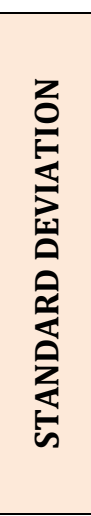 & s & 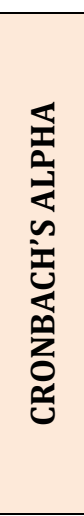 & 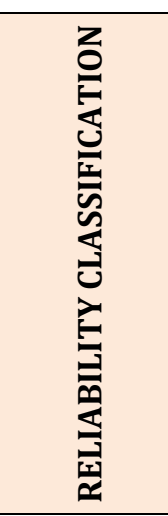 \\
\hline Scopes & 6.3 & 0.94 & 0.95 & 0.95 & \multirow{10}{*}{ 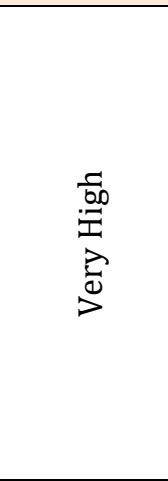 } \\
\hline Clarity is & 5.8 & 1.21 & 0.85 & 0.96 & \\
\hline Coherence & 6.2 & 1.01 & 0.95 & 0.96 & \\
\hline Criticality of items & 6.2 & 0.93 & 0.95 & 0.95 & \\
\hline Objectivity & 6 & 1.22 & 0.85 & 0.95 & \\
\hline Scientific redaction & 6.1 & 0.97 & 0.95 & 0.96 & \\
\hline Relevance & 6.5 & 0.92 & 0.95 & 0.96 & \\
\hline Sequence & 6 & 1.18 & 0.9 & 0.96 & \\
\hline Homogeneity & 6.1 & 1.16 & 0.9 & 0.96 & \\
\hline Currentness & 6.4 & 0.92 & 0.95 & 0.96 & \\
\hline Total & 6.1 & 1.05 & 0.9 & 1 & Very High \\
\hline
\end{tabular}

Table 2: Content validation using the reliability measures Cronbach's alpha and Content Validity Index (CVI) of the instrument nursing care technology in the prevention and management of hemorrhage in the third stage of labor. Florianópolis, SC, Brazil 2019.N 20.

Source: Developed by the author (2019).

Table 2 presents the classification of items scope, coherence, criticality of items, scientific redaction, relevance and currentness, which were considered excellent, with 0.95; the items sequence and homogeneity were scored 0.90 , while 0.85 was the score obtained by clarity and objectivity.

The items with the highest classification, with a Cronbach's alpha of 0.96 , in terms of the instrument's reliability were clarity, coherence, scientific redaction, relevance, sequence, homogeneity, and currentness. The items scope, criticality of items, and objectivity obtained a Cronbach's alpha of 0.95; that is, the judges considered all items to have very high reliability.
The instrument nursing care technology in the prevention and management of hemorrhage in the third stage of labor presented a CVI equal to 0.92 , which is considered excellent, and a Cronbach's alpha of 0.96; the judges classified the axes, domains and actions as highly reliable.

After assessing and analyzing data, the judges suggested new items addressing actions to be added to the domains: 2-Perform Physical/Obstetrical Assessment; 4 - Monitor pregnant women after determining risk; 5Manage labor with a partogram; 6-Identify and monitor failure to progress in labor; 7-Monitor and assess the use 


\section{Nursing \& Healthcare International Journal}

of oxytocin; 10-Prevent perineal trauma in the second stage of labor; 14 - Monitor placental detachment/discharge in vaginal deliveries; and 17 Communicate the multidisciplinary team in the event of hemorrhagic complications (placental retention or mother's collapse).

The judges' suggestions to change 11 care actions were accepted to improve the instrument. For instance, the word patient was replaced by woman, pregnant woman, or parturient; that is, the nursing care instrument in the prevention and management of hemorrhage in the third stage of labor was adjusted according to the judges' suggestions and based on evidence reported in the literature. Content was adjusted before completing and validating the final version.

\section{Discussion}

At the end of the content validation process that included the assessment performed by the experts, the instrument encompassed five axes, 20 domains and 92 care actions to record the needs of pregnant women, in order to support care delivery. No item was excluded from the instrument after the analysis performed by the experts. The 10 criteria recommended by Pasquali [28] obtained Cronbach's alphas $(\alpha)$ and Content Validity Indexes (CVI) well above the cutoff point established in the method adopted in this study, that is, Cronbach's alpha $\geq 0.70$ and CVI $\geq 0.80$. Yamada, et al. [37] adopted a Cronbach's alpha less than 0.70 to justify the exclusion of items of an instrument.

Data were analyzed using statistical tests. Cronbach's alpha was chosen because of its ability to reflect the level of agreement among items; the closer to one, the closer to $100 \%$ for the correspondence of items.

Even after validation, the assessment of criteria proposed by Pasquali [28,29] obtained values ranging from minimum to maximum. The items that obtained the highest Cronbach's alpha, 0.96, were: clarity, coherence, scientific redaction, relevance, sequence, homogeneity, and currentness. Scope, criticality and objectivity obtained Cronbach's alpha equal to 0.95. The judges considered that all the items presented very high reliability, which corroborates the instrument's reliability and internal consistency, the estimated reliability among judges and content validation. The instrument as a whole obtained a Cronbach's alpha equal to 0.96, while the judges considered the reliability of its axes, domains and actions highly reliable.
In a study validating a questionnaire addressing knowledge of asthma during childhood, Dourado, Maia and Araújo [38] report that a Cronbach's alpha equal to 0.88 , which was obtained for data concerning the caregivers' assessment, was a satisfactory index, considered by various studies to be an indication that data are relevant and pertinent. In this study, an even higher Cronbach's alpha, 0.96, was found.

In a study validating the content of a profile of nursing competencies of managers with higher education, Nogueira and Cunha [39] found Cronbach's alphas between 0.79 and 0.88 , that is, results were even lower than those obtained in this study. In a study intended to validate an educational game addressing sexuality among adolescents, Sousa, Oliveira and Coelho [40] found a Cronbach's alpha for the game as a whole equal to 0.88 , again, a result that is lower than the one found here. The study by Silva, et al. [41] reports a Cronbach's alpha equal to 0.76 for the content validation of a scale intended to predict hypertension complications.

Cronbach's alpha, chosen to assess this instrument's reliability, enabled to verify internal consistency and the estimate reliability among the experts. The Cronbach's alpha is based on the variance of individual items and covariance among items $[32,33,42,43]$.

The instrument nursing care technology in the prevention and management of hemorrhage in the third stage of labor obtained a CVI equal to 0.95 in the items scope, coherence, criticality of items, scientific redaction, relevance and currentness; 0.90 in the items sequence, homogeneity; and 0.85 in clarity and objectivity. In general, suggestions in the literature are for a minimum agreement of 0.80 when validating new instruments [35]. The total CVI obtained in this study was 0.92 . The general CVI obtained in the study conducted by Dourado, Maia and Araújo [38], which indicated their questionnaire was considered good to be applied to its target public, was 0.76 , a result lower than the one obtained in this study.

The study concerning the content validation of the profile of nursing competencies of managers with higher education conducted by Nogueira and Cunha [39] obtained CVIs between 0.88 and 0.95 .

The study conducted by Sousa, Oliveira and Coelho [40] to validate an educational game addressing sexuality among adolescents obtained a CVI of 0.94. A CVI equal to 0.98 was obtained by Silva et al. [41], when validating a scale intended to predict hypertension complications. The 


\section{Nursing \& Healthcare International Journal}

results obtained in both these studies were higher than the one obtained in this study, which was 0.92 .

CVI assesses agreement among judges in regard to the representativeness of a measure in relation to its content, by dividing the number of judges who rated an item as relevant or extremely relevant by the total number of judges (CVI for each item), which results in the proportion of judges who rated an item to be valid [34].

Composition and criteria were analyzed considering the instrument's reliability measure Cronbach's alpha (total of 0.96) and Content Validity (total equal to 0.92), assessed by 20 obstetrical nurses who considered the instrument's reliability as well as each of its items to be 'very high'; that is, the instrument was considered appropriate for use during care provided to pregnant women during labor, delivery and puerperium.

Melo, et al. [44] highlighted that expert-nurses with experience in teaching, research, care delivery and management are essential for the validation of an instrument. Hence, recruiting more experienced professionals ensures greater accuracy in the assessment of instruments.

Among future prospects, we highlight the validation of this instrument in other cultural contexts, as well as its clinical validation. Considering the importance of this technology, we will also register it as intellectual property.

\section{Conclusion}

This study enables understanding the process of content validation, essential for providing reliable instruments in the nursing field that support knowledge for safer clinical practice. Therefore, the validation of instruments with care actions is useful to properly perform appropriate nursing procedures.

Statistical measures such as Cronbach's alpha and Content Validated Index obtained very high values: total Cronbach's alpha of 0.96 and total CVI of 0.92 . Thus, the instrument validated in this study concerning nursing care technology used to prevent and manage hemorrhage in the third stage of labor is highly reliable.

\section{References}

1. Pan American Health Organization (2018) Assistance recommendations for prevention, diagnosis and treatment of obstetric hemorrhage.

Teixeira Rangel, RC, et al. Content Validation of the Instrument Nursing Care Technology in the Prevention and Management of Hemorrhage in the Third Stage of Labor. Nurs Health Care Int J 2019, 3(3): 000190.
2. Say L, Chou D, Gemmill A, Tunçalp Ö, Moller AB, et al. (2014) Global causes of maternal death: a WHO systematic analysis. Lancet Glob Health 2(6): e32333.

3. Grobman WA, Bailit JL, Rice MM, Wapner RJ, Reddy UM, et al. (2014) Frequency of and Factors Associated With Severe Maternal Morbidity. Obstet Gynecol 123(4): 804-810.

4. Fleischer A, Meirowitz N (2016) Care bundles for management of obstetrical hemorrhage. Seminars in Perinatology 40(2): 99-108.

5. Novo A, Subotic-Popovic A, Strbac S, Kandic A, Horga M (2016) Application of Agree II Instrument for Appraisal of Postpartum Hemorrhage Clinical Practice Guidelines in Bosnia and Herzegovina. Acta Inform Med 24(3): 211-214.

6. Suárez González JA, Beltrán YS, Machado MG, Benavides Casal ME, Pérez de Prado NP (2016) Impact of major obstetric hemorrhage in extremely severe maternal morbidity. Cuban Journal of Obstetrics and Gynecology 42(4): 464-473.

7. Ramler PI, van den Akker T, Henriquez DDC, Zwart JJ, van Roosmalen J (2017) Incidence, management and outcome of women requiring massive transfusion after childbirth in the Netherlands: secondary analysis of a nationwide cohort study between 2004 and 2006. BMC Pregnancy Childbirth 17(1): 197.

8. Smit M, Chan KL, Middeldorp JM, van Roosmalen J (2014) Postpartum haemorrhage in midwifery care in the Netherlands: validation of quality indicators for midwifery guidelines. BMC Pregnancy Childbirth 14: 397.

9. Mavrides, E, Allard S, Chandraharan E, Collins P, Green L, et al. (2016) Prevention and Management of Postpartum Haemorrhage. BJOG 124(5): e106-e149.

10. Westhoff G1, Cotter AM, Tolosa JE (2013) Prophylactic oxytocin for the third stage of labour to prevent postpartum haemorrhage. Cochrane Database Syst Rev (10): CD001808.

11. Knight M, Callaghan WM, Berg C, Alexander S, Bouvier Colle MH, et al. (2009) Trends in postpartum hemorrhage in high resource countries: a review and recommendations from the International Postpartum Hemorrhage Collaborative Group. BMC Pregnancy Childbirth 9: 55. 


\section{Nursing \& Healthcare International Journal}

12. Lutomski JE, Byrne BM, Devane D, Greene RA (2012) Increasing trends in atonic postpartum haemorrhage in Ireland: an 11-year population-based cohort study. BJOG 119: 306-314.

13. Rubio Alvarez A, Molina Alarcon M, Hernandez Martinez A (2018) Incidence of postpartum anaemia and risk factors associated with vaginal birth. Women Birth 31 (3): 158-165.

14. Al Zirqi I, Vangen S, Forsen L, Stray Pedersen B (2008) Prevalence and risk factors of severe obstetric haemorrhage. BJOG 115(10): 1265-1272.

15. Briley A, Seed PT, Tydeman G, Ballard H, Waterstone $\mathrm{M}$, et al. (2014) Reporting errors, incidence and risk factors for postpartum haemorrhage and progression to severe $\mathrm{PPH}$ : a prospective observational study. BJOG 121(7): 876-888.

16. Kramer MS, Berg C, Abenhaim H, Dahhou M, Rouleau $\mathrm{J}$, et al. (2013) Incidence, risk factors, and temporal trends in severe postpartum hemorrhage. Am J Obstet Gynecol 209(5): 449-457.

17. Nyflot LT, Sandven I, Stray Pedersen B, Pettersen S, Al Zirqi I, et al. (2017) Risk factors for severe postpartum hemorrhage: a case-control study. BMC Pregnancy Childbirth 17(1): 17.

18. Sheldon WR, Blum J, Vogel JP, Souza JP, Gülmezoglu $\mathrm{AM}$, et al. (2014) Postpartum haemorrhage management, risks, and maternal outcomes: findings from the World Health Organization Multicountry Survey on Maternal and Newborn Health. BJOG 121(1): 5-13.

19. Sosa CG, Althabe F, Belizán JM, Buekens P (2009) Risk Factors for Postpartum Hemorrhage in Vaginal Deliveries in a Latin-American Population. Obstet Gynecol 113(6): 1313-1319.

20. Chi Z, Zhang S, Wang Y, Yang L, Yang Y, et al. (2016) Research of the assessable method of postpartum hemorrhage. Technology and Health Care 24(2): S465-S469.

21. Sebghati M, Chandraharan E (2017) An update on the risk factors for and management of obstetric haemorrhage. Womens Health 13(2): 34-40.

22. Asterisk JN, Martin JG, Bercu Z, Shah J, Shekhani H, Peters G (2017) Postpartum Hemorrhage. Techniques in Vascular and Interventional 20(4): 266-273.

Teixeira Rangel, RC, et al. Content Validation of the Instrument Nursing Care Technology in the Prevention and Management of Hemorrhage in the Third Stage of Labor. Nurs Health Care Int J 2019, 3(3): 000190.
23. Sittiparn W, Siwadune T (2017) Risk Score for Prediction of Postpartum Hemorrhages in Normal Labor at Chonburi Hospital. J Med Assoc Thai 100(4): 382-388.

24. Contandriopoulos, Pierre A, Champagne F, Potvin L, Denis JL, Boyle P (1997) Knowing how to prepare a research: definition, structure, financing, 2.

25. Wood L, Geri, Judith Haber (2001) Nursing research: methods, evaluation, critique $4^{\text {th }}$ (Edn.), Rio de Janeiro, RJ: Guanabara-Koogan.

26. Polit, Denise F, Cheryl Tatano Beck, e Bernadette P Hungler (2011) Fundamentals of nursing research methods, evaluation and utilization $5^{\text {th }}(E d n$.$) , Porto$ Alegre, RS: Artmed.

27. Lynn MR (1986) Determination and Quantification of Content Validity. Nurs Res 35(6): 382-385.

28. Paquali L (1997) Psychometrics: theory and applications. Brasilia: UnB.

29. Paquali L (2010) Psychological Instrumentation: Fundamentals and Practices. Porto Alegre, RS: Artmed.

30. FAR0, Ana Cristina Mancusso (1997) Delphi technique in the validation of nursing interventions. Rev Esc Enf USP 31(1): 259-73.

31. Cronbach LJ (1951) Coefficient alpha and the internal structure of tests. Psychometrika 16(3): 297-334.

32. Riul FC, Moraes CR, Severo F, Vendrameto MC, Lustosa Costa R (2016) Reliability of the Questionnaires: An analysis of the Internal Consistency of the F-Scale based on Cronbach's Alpha Coefficient. XIII SEGET Symposium on Excellence in Management and Technology. Skills Development Facing the Challenges of Tomorrow. Rio de Janeiro.

33. Luis Policani FA, Rodrigues SG (2005) The reliability assessment of questionnaires: an analysis using Cronbach's alpha coefficient. XII SIMPEP.

34. Rubio DMG, Berg Weger M, Tebb SS (2003) Objectifying content validity: Conducting a content validity study in social work research. Soc Work Res 27(2): 94-104. 


\section{Nursing \& Healthcare International Journal}

35. Grant JS, Davis LL (1997) Selection and use of content experts for instrument development. Res Nurs Health 20(3): 269-274.

36. Brazil (2012) Resolution 466 of the CNS dealing with research on human beings. The resolution was approved by the Plenary of the National Health Council (CNS) at the 240th Ordinary Meeting, Brasília. Official Journal of the Union.

37. Alves YBF, Conceição de Gouveia SVL (2009) Development and validation of Ferrans \& Powers Quality of Life Index: wound version. Revista da Escola de Enfermagem da USP 43: 1105-1113.

38. de Oliveira Dourado CAR, Maia F, Araújo W (2017) Knowledge Questionnaire On Asthma In Childhood: Application And Validation. Electronic Review of Estácio Recife 3(1): 1-12.

39. de Oliveira Nogueira V, Kowal Olm Cunha IC (2018) Validation of competency profile content of higher education nurse managers. Rev Cuidarte 9(1): 19982006.

40. de Sousa MG, de Oliveira EML, de Mendonça Figueirêdo Coelho M, Miranda KCL, Teixeira
Henriques ACP, et al. (2018) Validation of educational game about sexuality for adolescents. Cuidadoe Fundamental 10 (1): 203-209.

41. Bauer de Camargo Silva AE (2010) Patient' safety: challenges for nursing research and practice. Rev Eletr Enf 12(3): 423.

42. Monteiro da Hora HR, Rego Monteiro GT, Arica J (2010) Reliability in Questionnaires for Quality: A Study with Cronbach's Alpha Coefficient. Produto \& Produção 11(2): 85-103.

43. Souza AC, Alexandre NMC, Guirardello EB (2017) Psychometric properties in instruments evaluation of reliability and validity. Epidemiol Serv Saude 26(3): 649-659.

44. Melo RP, Moreira RP, Fontenele FC, Carvalho de Aguiar AS, Joventino ES, de Carvalho EC (2011) Criteria for selection of experts for validation studies of nursing phenomena. Rev Rene 12(2): 424-431. 